\title{
Running for Elected Office: A Ten-Week Political Campaign Simulation for Upper-Division Courses
}

\author{
Lyn Kathlene, University of Nebraska at Lincoln \\ Judd Choate, Baker University
}

\begin{abstract}
Elections are a central feature of Ethe U.S. system of government. Therefore, it is important that undergraduates, especially political science majors, acquire a substantive understanding of the electoral process. To help students gain this understanding, we have developed a simulation through which undergraduates gain firsthand knowledge of the campaign process. In this simulation, students assume the roles of candidates, staffers, or journalists and undertake a ten-week campaign that ends with a public debate and election. The simulation is designed to be an intensive, multidisciplinary exercise that is flexible in duration and sophistication as well as highly competitive and rigorous for majors and nonmajors alike. Students find the simulation to be both educational and a welcome diversion from the standard lecture format.
\end{abstract}

\section{Introduction}

The "Running for Elected Office" simulation challenges students to apply theories and research on political campaigns, become knowledgeable and conversant in current affairs, and develop and hone skills

Lyn Kathlene is associate professor of political science at the University of $\mathrm{Ne}$ braska at Lincoln. Her research interests concern the impact of gender on policy formulation and participatory policy analysis. She has published in various journals and edited volumes including the American Political Science Review, Journal of Politics, and Journal of Policy Analysis and Management.

Judd Choate is assistant professor of political science at Baker University. His research interests include congressional norms and institutionalization. He is contributing a chapter to Indiana Politics and Policy (Simon \& Schuster, forthcoming). related to their specific roles. The simulation has enough structure and flexibility to be adapted easily to a wide variety of upper-division American government courses. While it may be workable in lower-division courses, we believe that for the simulation to reach its full potential the class should have less than 30 students, a relatively high percentage of self-motivated students majoring in political science or related fields, and students who have developed good writing, research, and analytical skills. Of course, all students in upper-division courses do not necessarily possess the latter two characteristics, but older students are more likely to possess them than younger students in an introductory American government course.

The simulation has been employed in two very different settings: an upper-division presidency course at a small liberal arts school and a senior honors seminar on gender politics at a large research university. The following discussion of the simulation will draw upon these respective experiences, demonstrating the simulation's adaptability for use in significantly different courses while noting how various situational factors impact its use in unique and important pedagogical ways.

\section{Simulation Design and Types of Events}

\section{Design}

For the simulation, students are randomly assigned to one of two groups: (1) the candidates and their campaign staffs, and (2) the media. The number of candidates/staffs can be as few as two and as many as needed, according to the campaign level (primary versus general) and size of the class. In the presidency class, there were three candidates (Republican, Democrat, and Independent) mirroring the 1996 campaign; in the gender politics class, two candidates ran for an open Senate seat. The number and variety of the media are similarly flexible, and having students simulate different types (newspapers and news magazines) and levels (national and state/ local) provides an interesting contrast in news coverage.

To provide students with a foundation from which to develop their roles, the candidates and media should be based on actual persons/ sources selected by the instructor and/or students. For example, in the presidency class, the candidates were based on Jack Kemp (Republican), Diane Feinstein (Democrat), and Ross Perot (Independent). Each staff was responsible for researching their politician to develop the candidate's initial political and personal profile, which introduced students to the wide variety of information available on elected officials via the World Wide Web, popular journal abstracts, and national and local newspaper indexes. In the gender politics class, Barbara Mikulski (Democrat) and Nancy Kassebaum (Republican) were the candidate models. In the latter course, the instructor included a biographical chapter on each woman in the course packet, thereby integrating readings and class discussion.

Students assigned to the media groups are required to mimic their respective sources' typical campaign coverage, taking into account the ideological leaning of the newspaper/journal, the type and depth of reporting customary for the media source, and its consumer characteristics. Students playing the media are 
required to do independent research on their assigned source to develop their media personas.

One class per week should be reserved for simulation activities. For the ten weeks of the simulations described here, each Friday served as simulation day. Instructions for the weekly events should be provided to the students during the simulation introduction immediately following their role assignment. The event guidelines and weekly assignments for the candidate/staff and the media are reproduced in Appendices A and $\mathrm{B}$, respectively.

\section{General Structure of Weekly Events}

Nearly every week the simulation has two main assignments that engage students in multiple learning tasks. The interactive component, in which the candidate/staff and media groups come together in a "public forum," is typical of simulations. It provides a "hands-on" experience, thereby facilitating experiential learning. The writing component, in which each student prepares a rolespecific assignment, is a reflective thinking exercise. Together, these two components accommodate di- vergent learning styles (Fox and Ronkowski 1997). For example, week 2 consists of an open press conference where each candidate announces his/her intention to run for office and afterwards takes questions from the press. Following the press conference, each campaign staffer must write a one-page internal memo advising his or her candidate on the areas in need of improvement. In addition, each candidate must write a one-page internal memo to his or her staff regarding the last event and desires for the next event, and each journalist must write a one-page news article for his or her respective publication.

The role-playing and writing assignments serve to develop and reinforce verbal and written communication skills. These components require the candidates and staffers to work together to prepare for substantive questions from the media and to develop political strategies based on all the candidates' strengths and weaknesses. Members of the media must prepare questions relevant to the campaigns, the current election cycle, and their readers. In addition, the media and candidates learn how to interact

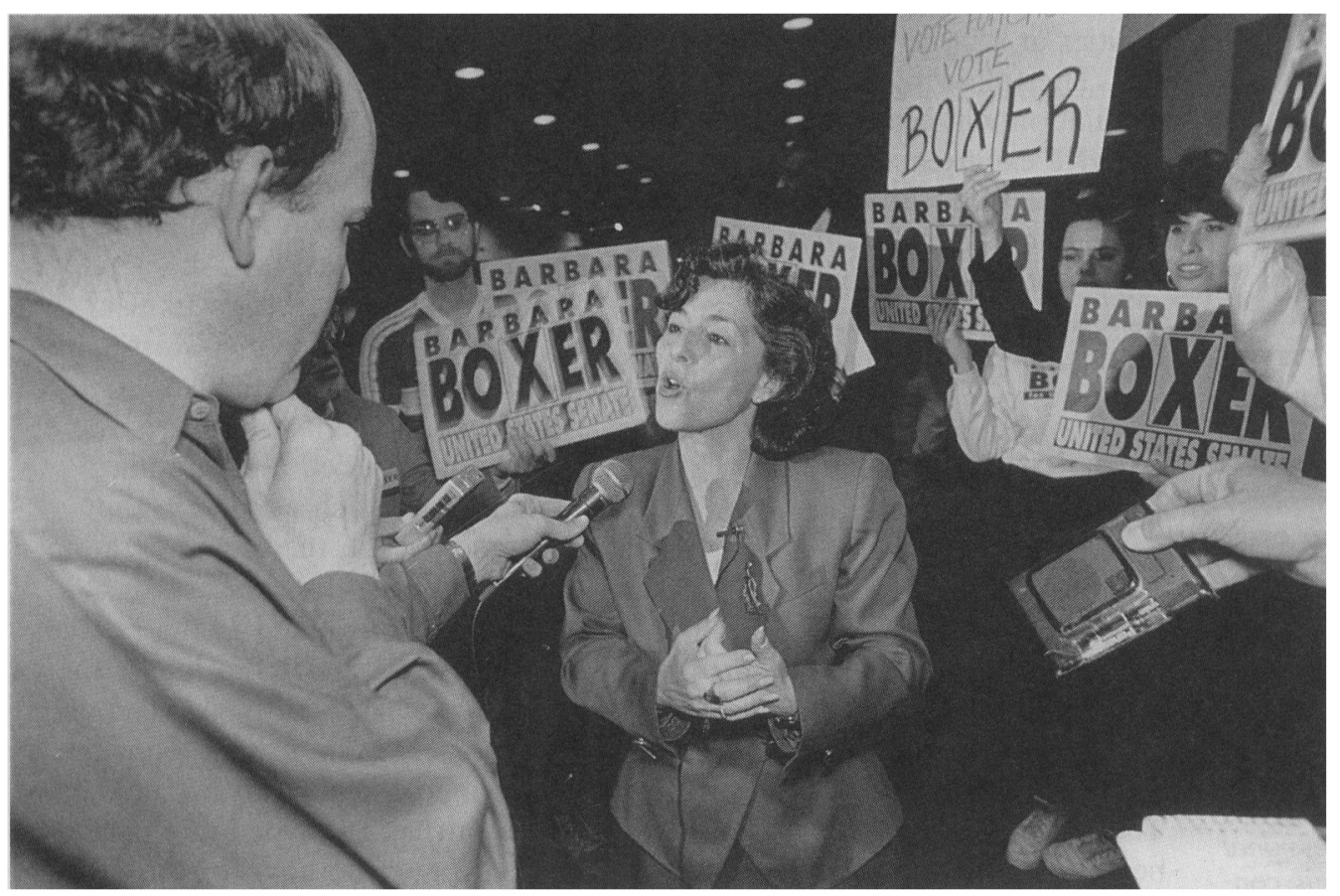

Barbara Boxer (D-CA) speaks with members of the media during the 1992 California State Democratic Convention. (Ted Soqui, Impact Visuals, 1992). spontaneously during the question and answer portion of the press conference. The weekly written assignments promote the development of critical and analytical thinking skills since they require candidates and staffers to respond to the internal dynamics of their political campaigns. The journalists learn how information is shaped via subtle methods of information ordering, information coverage and noncoverage, use of adjectives, horserace coverage, and issue focus. The distribution of news articles to everyone in the class creates a feedback loop by demonstrating how previous news coverage influences future campaign strategies. Students quickly learn that the relationship between candidates and the media is simultaneously symbiotic and adversarial. To emphasize these political lessons, the instructor can conduct "debriefings" periodically during the simulation and/or require students to critically analyze these aspects through a midterm paper or an exam question.

\section{Types of Special Events}

Three events in the simulation require elucidation due to special technical requirements. Each candidate must create a campaign brochure and a TV commercial, both of which can be more or less sophisticated depending upon the instructor's expertise and campus facilities. The final event, an election debate, can be a campuswide educational forum, if the in-

\section{A successful campaign simulation should include components such as interaction between candidates and staff and candidates and the media.}


structor utilizes a variety of personal and institutional incentives.

Before discussing the technical aspects of producing campaign brochures and television commercials, it is important to highlight the pedagogical benefits of these visual assignments. Still and moving pictures are persuasive campaign tools that are used to develop and manipulate candidate images and public opinion. Intangibles such as honesty and integrity, personal characteristics such as family status, and public policy stances are all conveyed through visual images. The experience of creating and responding to these images forces students to expand their critical thinking skills to the visual world.

With available software programs, digital image scanners, canned video image clips, and videotaping equipment, students can create high-quality campaign brochures and professional TV commercials. Prior to implementing the simulation, the instructor should determine the oncampus availability of and student access to such resources. Instructions concerning available resources and support staff (if applicable) should be given to the students in the campaign groups at the beginning of the simulation. Even given this preparartion, we found that "mastering" technical aspects can be time-consuming and may be beyond the capabilities of the average political science student; but this can be overcome with a bit of imagination or coordination with other course instructors. For example, communication or journalism departments usually offer courses that teach students how to create text and pictorial layouts. In addition, broadcast media or film studies courses routinely teach students how to create professional videos. Coordination with instructors of these courses can result in class assignments that further the objectives of all concerned. For instance, in the presidency class, communication majors and faculty helped make the commercials to fulfill requirements for a different course. Alternatively, you may be able to draw upon the experiences of students in the class. In the gender politics class, one student had access to a local professional film studio and arranged for the filming of the candidates' commercials. Admittedly, the latter circumstance, while highly desirable, is a rare occurrence.

If collaboration with other instructors and courses or reliance upon students' expertise is not possible, a "low-tech" alternative exists that meets all the same pedagogical goals. The main advantage to the higher-quality production is the excitement and satisfaction students gain from creating a professionaltype product (and the precedent of setting up cross-disciplinary, coordinated course instruction on campuses is a worthwhile indirect benefit). Originally, however, the simulation was designed without the thought of technological sophistication. Students were asked to create campaign brochures using only the basic functions and layouts within common word-processing programs. The images can be photographs pasted onto the original hardcopy text layout and photocopied to combine images with words. For the TV commercials, videotaping is easily done with a video camera, tripod, and a well-lit setting. Two recorders and a television are all students need to edit a videotape. Most likely, this equipment is available through the college/university's instructional equipment services.

The last "special event" requiring preplanning is the final debate and election. In order to enhance the intensity and excitement of the event, we recommend instructors attract a large audience for the debate. Thus, students should be asked to ask all their friends to attend. We discovered, however, that relying on only friends of students is unlikely to produce a large audience. So, the instructor should attempt to increase the attendance as well. One easy method to increase attendance is to offer bonus points to students in the instructor's other class(es). In the gender politics class, this method alone produced over 100 audience members. Another method, which is probably more applicable to small schools, is to advertise the debate and election on campus by having students put up flyers in their dorms, fraternities, and sororities. Colleagues should also be asked to announce the debate and, perhaps, even offer bonus points for attendance. Having many people in the audience, especially if they are unfamiliar with the candidates, creates an uncertain election outcome. Though the intent is to create a large public forum for the debate, there are important benefits that accrue to the audience as well as the department. The debate offers audience members an opportunity to engage in a process they likely have only seen on television. The knowledge that they can ask questions of the candidates and vote for their favorite helps keep audience members interested and focused on the candidates. To increase the realism and excitement of a campaign, candidate brochures can be handed to audience members upon entering the auditorium. In addition, we recommend a public viewing of the TV commercials prior to the commencement of the debate. Employing a moderator (the instructor or a prominent school official) and publicly announcing the rules governing the debate adds another dimension of formality and reality that keeps each round of questions short and lively. From a departmental perspective, having students from outside the course attend one of its functions is good advertising for the course and the department. In fact, if the instructor feels especially confident about the quality of the debate, he or she might consider contacting a local newspaper or TV station to cover the event.

\section{Student Evaluation}

In the two examples discussed here, the written assignments serve as the basis for student grades. Since each successive week of the simulation brings with it a writing assignment based on the students' assigned roles, grades are based predominantly on the ingenuity, creativity, and quality of the written assignments. The exceptional students generally rise to the occasion, producing campaign letterhead, stickers, and other items that separate their work from the others cam- 
paign workers. The same phenomenon occurs among the media correspondents. Enthusiastic students write their newspaper stories in column form, with headlines, bylines, pictures, and elaborate typesets. In fact, during the presidential simulation, one student used a fraternity yearbook picture for the editorial byline, thus separating his work as a newswriter from that as a columnist.

Not surprisingly, there can exist a substantial difference between a student's participatory performance and that student's ability to convey his or her knowledge and understanding on paper. To account for this, a peer evaluation component can be included, thus allowing students of each campaign and the different media sources to grade the efforts of fellow group members. Not only does this improve the quality of the simulation by adding peer pressure to the mix, it provides the instructor with a better sense of who is truly working to make each campaign run effectively.

In addition to the standard evaluation inducements, the simulation grade itself can be used as an incentive to encourage high-quality participation among the campaign workers and media correspondents. During the presidential simulation, the instructor guaranteed an automatic " $A$ " to students on the winning campaign. The news correspondents were also guaranteed an " $\mathrm{A}$ " if, based on their knowledge of the candidates, they correctly predicted the outcome of the election in their final preelection editorial. Not only did the quality of the campaign improve, but many students actively worked to increase the number of supporters at the final debate, conducting a get-out-the-vote-campaign of sorts. These efforts led to a large, attentive audience, which included friends, faculty, and parents.

In short, we have found that students participating in the campaign simulation produce high-quality, ingenious work. This type of experiential learning encourages students to work hard while providing a forum to showcase their abilities. As a consequence, the evaluation process takes care of itself.

\section{Lessons We Have Learned}

While the numerous benefits previously cited illustrate the effectiveness of the campaign simulation, pitfalls exist that can cause problems for instructors and students alike. For instance, the level of competition that develops between and among the candidates and the competing staffs can become extraordinarily intense, producing both fierce intraparty loyalty and exaggerated levels of interparty rivalry. Clearly, the high-quality products produced during the simulation could be attributed, at least in part, to the intensity of this competition. Moreover, the competition mimics real-world campaign races; we see this as an indicator of the simulation's success. However, creating this dynamic in the classroom, where two-thirds of the course is devoted to activities other than the simulation, can be quite disconcerting and requires instructor intervention.

In the gender politics course, the degree of competition reached such a high level by the simulation's sixth week that during the Monday and Wednesday class periods each candidate and her staff sat on opposite sides of the room. This self-selected seating arrangement was a physical reflection of the class atmosphere, and discussions of the day's readings oftentimes reflected the adversarial party dynamics. Beyond the classroom, students from both camps sought out the instructor to complain about how the other group "spied" on them during and outside of class. In addition, both parties lodged several complaints about the opponent's "unfair" campaign practices. Amazingly, the media were largely ignorant of these disputes, and only became aware of them during a class discussion of the mounting problems.

At the time, the instructor's solution was to constrain the adversarial behavior by instituting a variety of rules to create a more "even" playing field and creating penalties for violating the new rules (e.g., deducting grade points for mudslinging in the final debate). Unfortunately, this had the practical effect of restricting flexibility for the campaigns. Though the simulation was clearly a success (see the student evaluations in the next section), it is now apparent that the mounting competition was a natural outgrowth of campaigning and should have been discussed as such. The students could have learned far more about politics and human nature if class time had been spent examining and analyzing how and why the same dynamics were present in actual political races. The media's ignorance of this tension should have been discussed as a weakness of the campaigns to "use" the media, as well as a failure by the media to engage more actively and realistically (e.g., talking with staffers outside of class to glean as much insider information as possible for the next week's event).

Interestingly, in the presidency course, the competitive aspects of the campaign did not spill over into the nonsimulation days. In fact, the simulation did much to increase student participation during "normal" class periods. As students worked together, they became more familiar with one another and less inhibited during class discussions. The difference may have been related to the inclusion of an independent candidate. Having a third candidate may have minimized excessive competition by discouraging the develop- 
ment of an "us against them" attitude. Of course, the less contentious atmosphere simply may have been a function of the class personality.

If competition becomes excessive, we recommend scheduling a postelection social event to help reunite the class. In the gender politics course, the social event was a pizza party at the instructor's home. Making pizzas together was not only fun, it helped to defuse the competitive feelings. The class atmosphere after the postelection social event was markedly different than during the latter half of the simulation.

\section{Lessons the Students Learned}

Mid-term and end-of-semester student evaluations confirmed our perceptions that the respective simulations were effective and engaging. In each class, students were asked to write a short essay in response to the question, "Thinking about the role you played in the simulation, what have you learned about campaigning in general and women's campaigns specifically?" The students were told that there was no right or wrong answer, only that they needed to complete the essay. The purpose of the question was to have students critically reflect upon their experiences and to collect feedback about any necessary changes to the simulation.

Excerpts from the candidates' responses highlight the realism of the simulation. Students acting as candidates credited the simulation with encouraging them to think strategically about issue presentation and to understand the personal emotions that emerge as a consequence of the media spotlight.

When my group and I sat down to come up with a platform, I wondered if we should include women's issues. On the one hand, I did not want to alienate male voters. I also did not want to be pigeonholed as only concerned about the rights of women. On the other hand, these issues are very important to me and I thought they should be included. . . I I admit I was a bit naïve when I went into this.... I have learned a great deal since then and I am working very hard to become articulate about a wide range of issues. Overall, this has been an incredible learning experience. (Democratic candidate for Senate)

One of the things I learned in the simulation is that for better or worse you have to let your staff do their work. Any policy question is fair game. There are so many things that the press can choose to ask you about. You have to be prepared to talk about any issue that they ask you. Hence, you must rely heavily on the hard work of your staff. (Independent candidate for president)

I feel as though this were a real campaign, for a real seat in the Senate, and I felt all the emotions that go with that-competitiveness, aggressiveness, nervousness, and jubilation when something goes well. ... I have significantly refined my public speaking style and ability, always with an eye toward strategy and the persona that I portray. ... One thing it has brought to my attention, however, is that media attention and questions to a woman candidate focus inordinately upon women's issues. This is a difficulty because in an actual race this bias could alienate male voters and make the candidate appear one dimensional. Overall, I feel that this simulation has been a rewarding experience. It has forced me to become informed and given me an enriched understanding of the political arena. In fact, in trying my hand at this game, I find that I enjoy it so much that I am seriously considering a career in politics. (Republican candidate for Senate)

The media asked various questions of me with respect to policies I sometimes hadn't given much thought. This made me understand how real candidates must feel during town hall debates.... Having good staff members is very important so you can stay on top of the issues.... In addition, the personal lives of the candidates must be beyond reproach with respect to the activities they engage in and "off the record" things they say. (Republican candidate for president)

Campaign staffers learned somewhat different lessons than the candidates. They saw themselves as part of a team focused on fashioning a viable candidate, prepared to discuss a wide range of issues. In addition, campaign members found creating positive images, making strategic changes, and interacting with the media important to sustaining a successful candidacy.

I have learned how important it is for everyone on a campaign team to know every aspect of their own candidate's issue stands as well as the opponent's stands on the issues.... When we worked on our campaign brochures, I realized how much time and planning must go into making them. While we were shooting the pictures of [our candidate] for our brochure, we went to a construction site on campus. At first, I didn't think that they would let us near it, but to my surprise they invited us in.... All of the construction workers on the site were men. They seemed very interested in what we were doing. ... but then when we were leaving the site the whistling began.... At this point, I thought of the problems that women must encounter when they deal with men as they are campaigning. (Republican senatorial candidate staffer)

I was press secretary for [the independent presidential candidate]. As a result of this experience, I have learned the importance of pushing a consistent set of messages to the press and how to coach my candidate to stay on message in the face of hostile press coverage. ... My role, above all, was to obfuscate at the drop of a pin.... Between us, I found it to be a somewhat seamy task, but I'm proud of the results. We got the best of both results, we defined expectations and didn't have to govern. (Independent presidential candidate staffer)

The predicament incurred over the decision to use negative campaigning; the compromises made in the portrayal of a candidate as more than a women's issues candidate; the strategic manipulation used in the formulation of policy issue statements, campaign materials, and political speeches; the norms adhered to in the framing of a viable image for a woman candidate; the personal convictions bridled in an effort to foster mass media support of a feminist candidate-these are only a few of the myriad of issues grappled with 
as the press secretary. (Democratic senatorial candidate staffer)

I believe, as a very naïve and inexperienced political science student, I learned a great deal about the campaign process and the necessary components of an election team. There is no way to understand, apart from working on the simulation, the work involved in participating in a campaign. Although I learned more pertaining to my specific role, I also gained from working with others on the team. The debate itself took far more preparation than I would have anticipated. (Republican presidential candidate staffer)

Members of the media became acutely aware of how subjective "objective" reporting can be, prompting a greater appreciation of the media's influence. As knowledgeable political observers, they were able to appreciate the pressure on candidates to understand the issues and facilitate a cooperative arrangement with the media.

First of all, it quickly became apparent that it can be very difficult to objectively report the facts of an interview or debate without unintentionally forming the article into a personal political agenda.... From observing the two camps, it was easy to see the exercise transform from just a creative class assignment to a fervent competition requiring extended hours of practice, research, and polishing .... Both [candidates] were very well-versed in front of the camera, but the pressures on a candidate under national media coverage must be unbelievable. (Journalist for a national magazine)

I learned about writing newspaper articles and experiencing dead-

lines. ... I really didn't pay attention to politics before this simulation. I have low political efficacy. But, after experiencing it first hand, I feel I pay attention more, and I will keep a closer eye on the next presidential election. I believe I grasped the concept of a presidential election through this simu- lation. (Journalist for a national newspaper)

Playing a role in the media has given me a chance to see the final work of the two campaign staffs and has also made me consider how important the role of the media is in any campaign. I realize now that I basically have two people before me and that it is up to my discretion to report and portray these two people as I wish.... One thing that I have learned about campaigns is how "on" the candidate must be at all times. Candidates have only limited opportunities during which they have the chance to present themselves to the public and to make themselves heard. (Journalist for a local newspaper)

The campaign simulation has increased my awareness about the important issues in this election. I've had to listen more closely to the news and watch more political talk shows and more C-SPAN than I usually do in order to try to find a less typical question... I've been impressed with the knowledge and the professionalism of the candidates. They've had to keep up-to-date on every issue in case one of the media asks them a question. They've also taught me that even a simulated campaign causes competition and stress. ... I can't imagine what it would be like for candidates who are campaigning every day, all day, for months. (Journalist for a national newspaper)

Based on the evaluation comments, it is apparent that regardless of the role they played, students found the simulation made them more knowledgeable about current affairs and better able to understand how and why campaigns become hypercompetitive, all of which extended their understanding of campaign politics.

\section{Conclusions}

This article outlines two ways to use the "Running for Elected Office" simulation. We argue, however, that it is highly flexible and not constrained by the parameters established here. For instance, instructors with larger upper-division courses may wish to simulate a primary or caucus election in order to increase the number of candidates. In addition, the media roles could be expanded to include TV reporters who file video packages of the weekly event, much as network news correspondents might. In short, as long as the central premise of the simulation is maintained, the instructor can alter or add to it so as to create the best possible fit for his or her class. As elections are a central feature of the U.S. political system, a modified version of this simulation is relevant to any number of American government courses. We anticipate that it could be adapted for classes on women in politics, the presidency, Congress, state and local government, and political parties, to name just a few.

The "Running for Elected Office" simulation is a highly effective pedagogical tool. It forces students to use what they learn in lectures and readings by assuming unfamiliar roles and mimicking a "real" political campaign (Endersby and Webber 1995). Majors and nonmajors readily engage in this intensive learning experience, generating enthusiasm and high productivity. Students as well as instructors look forward to the weekly excursion into the political process. Stated bluntly, this simulation is both educational and fun, further illustrating the benefits of experiential learning.

\section{References}

Endersby, James W., and David J. Webber. 1995. "Iron Triangle Simulation: A Role-Playing Game for Undergraduates in Congress, Interest Groups, and Public Policy Classes." PS: Political Science and Politics 28(September): 520-23.

Fox, Richard L., and Shirley A. Ronkowski. 1997. "Learning Styles of Political Science Students." PS: Political Science and Politics 30(December): 732-37. 


\section{Appendix A \\ "Running for Elected Office"}

\section{Candidate's Guidelines}

The class will be divided into groups. Two or more groups will be composed of a candidate running for elected office and her or his campaign staff. One group will be composed of reporters representing a variety of national, state, and local print media.

Candidates running for office will be a personal and political composite of (1) an actual viable political candidate (family background, political experience, policy issue stances, etc.-most of which can be found online or in the literature provided); (2) responses to this year's election issues; and (3) the personality of the student playing the role of the candidate.

\section{Guidelines for the Campaign Groups}

Each person in the group has a special role to play in the campaign. The roles are:

1. Candidate

2. Campaign Chairperson (chief policy adviser; designs campaign brochures)

3. Press Secretary (writes press releases, responds to press inquires; advises candidate on how to handle the press and how to respond to the opponent's campaign)

4. Public Relations Adviser (designs and directs filming of TV commercial; advises candidate on image)

While the candidate's position on issues and her or his public/ personal image will be based on an actual politician, each campaign group may embellish upon these characteristics and policy interests to the extent that they are congruent with the candidate's "background."

Each campaign staff will need to carefully determine the candidate's strengths and weaknesses and build a campaign accordingly. The staff will also want to examine the opponent's background and use information collected to benefit their candidate.

Each staff person will advise the candidate in discussion groups (usually held on Friday, although out of class meetings are allowed and encouraged) and will have to write memos of advice to the candidate (the due dates for these memos are listed below). Each candidate will have to issue a memo to her or his staff regarding concerns about past events and desires for future events.

\section{Schedule}

Each Friday is devoted to the simulation.

\section{Week Event}

1. Meet to discuss strategy for the first press conference. You will want to discuss your candidate and her or his opponent(s). Be prepared to emphasize the strengths of your candidate and know how to address what you think are your candidate's weaknesses. Part of your strategy should be anticipating the strategy of the other campaign, including how to combat the opponent's strengths that may be your candidate's weaknesses, and how to create a unique candidate image so that the voters have a "clear" choice.

2. First "open" press conference based on biographical background of candidates. Each candidate holds a 10-minute session. Campaigns will meet afterwards to discuss impressions and draft campaign issue statements that will be released the following Friday. Each staff person will write a short memo (one page) based on her or his evaluation of the first press conference advising the candidate about future strategies. Each candidate writes an internal memo to staff.
Memos due following Monday.

3. Candidates provide a one-page written issue statements to press (please make enough copies for everyone in the class including the instructor). During the first half of class, media prepares questions. During the second half of class, a press conference based on the campaign issue release is held. Each staff person will write a short memo (one page) based on her or his evaluation of the second press conference advising the candidate about future strategies. Each candidate writes an internal memo to staff. Memos due following Monday.

4. First candidate debate, sponsored by the League of Women Voters. Candidates provide campaign brochures to the press (please bring enough copies for everyone in the class); press provides campaign staffs with issue areas to be addressed in debate; League of Women Voters [instructor] provides debate rules to press and candidates. The debate is held the last 30 minutes of class. A campaign PR statement about the staff's interpretation of the debates is provided to each candidate. Each candidate writes an internal memo to staff. Memos due following Monday.

5. TIME OFF from campaign simulation. [Midterm scheduled]

6. Each campaign will film their TV commercial during this week. Media will do a poll of their readers: Do not come to class. Article on poll results due following Wednesday.

7. Campaigns receive poll results. First airing of political commercials. "Meet the Press" roundtable discusses the race, moderated by political scientist [instructor's name]. Campaigns watch and meet afterwards to develop a press release in response to the media pundits and write a prepared speech for the next event. Each candidate writes an internal memo to staff. Press release and memos due following Monday.

8. Each candidate makes a 10-minute speech followed by a 10minute press conference. Each staff person will write a short memo (one page) based on her or his evaluation of the media's reception of the speeches to advise the candidate about future strategies. Each candidate writes an internal memo to staff. Memos due following Monday.

9. TIME OFF to prepare for debates. Prior to the debate, the LWV [represented by the instructor] and the campaign staffs will agree upon the terms of the debate regarding whether or not a list of the journalists' potential questions are made available to the candidates before the debate. Debate questions from each media source are due the following Monday. If the candidates decide to restrict the debate to submitted questions, each campaign will also receive the questions on the following Monday.

10. Public Debate and Election. Thursday, $7 \mathrm{pm}$. Invite all your friends. Campaigns hand out brochures to the audience. Debate begins with airing of television commercials. The debate is sponsored by the League of Women Voters, and features a panel of distinguished journalists moderated by political scientist [instructor's name]. Candidates will receive initial question from panelists every other turn. The candidate to receive the first question will be determined by a flip of the coin prior to the commencement of the debate. For each round of questioning, the candidate who receives the initial question will have two minutes to answer, followed by a one-minute response from the opponent, with a 30 -second rebuttal opportunity from the first candidate. The last 15 minutes will be reserved for audience questions. Upon the conclusion of the debate, citizens in the andience will complete their election ballots and drop them in boxes at the auditorium exits. The press will conduct exit poll interviews with at least 10 people and write up their prediction of the winner based on the results. Exit poll and election results will be announced the following Monday in class.

11. Monday. During the first half of class members of the media form an election watch panel to discuss their reader/listener exit polls and make their predictions for the winner. Election results are announced. During the second half of class the winner and loser each appear before the press with the appropriate acceptance or concession speech.

Thursday or Friday night: End of election year pizza party at instructor's house. 


\section{Appendix B \\ "Running for Elected Office"}

\section{Media Guidelines}

The class will be divided into groups. Two or more groups will be composed of a candidate running for elected office and her or his campaign staff. One group will be composed of reporters representing a variety of national, state, and local print media.

Candidates running for office will be a personal and political composite of (1) an actual viable political candidate (family background, political experience, policy issue stances, etc.-most of which can be found online or in the literature provided); (2) responses to this year's election issues; and (3) the personality of the student playing the role of the candidate.

\section{Guidelines for the Media Group}

Each person in the group will be a reporter for one of the following five newspapers or journals:
1. National newspaper (e.g., The New York Times, The Washing- ton Post)
2. National news magazine (e.g., Newsweek, Time)
3. Specialized magazine (e.g., Ms., $C Q$ )
4. State's large city newspaper
5. Local city's newspaper

Each reporter has her or his own particular interest in the campaign, based on the readership of her or his newspaper or journal, which includes the geographical distribution of the news source (e.g., national vs. state vs. local) as well as the readers' socioeconomic status and ideological leanings.

Each reporter should use biographical backgrounds provided for each candidate supplemented by information found on the Internet or in the library to develop their early news stories and questions for the first press conference (week 2). Afterwards, the reporters will need to keep abreast of the issues salient to their news source in this year's election season. Current issues, in combination with each candidate's personal and political histories and campaign public relations efforts (including press releases, campaign literature, speeches, and TV commercials) will provide the basis for future articles, press conference questions, questions asked during the debates, and public opinion polls of readers.

Most weeks, the press will have to be prepared to ask the candidates questions, which can include questions about the actions or statements that arise from the other candidate's campaign. It is up to each reporter to determine how personal he or she wants to make the questions.

A public opinion poll will be done once during the campaign. Each reporter will select 20 "subscribers" (these can be friends, family, or anybody you can get to play the game) to read the set of articles you have written about the campaign. You will ask each of the 20 subscribers to answer a set of questions you have developed about the race. You will write up an article describing the results of the poll.

Near the end of the race (during week 9), your newspaper or magazine will want to endorse one of the candidates. In this exercise, you will write an editorial article explaining the reasons for picking one candidate over the other. Remember, you will want to reflect the opinions of your readership as well as represent the politics of the actual editorial board (by reading editorials in your news source throughout this year's campaign session, you should be able to determine which candidate the newspaper or magazine would endorse).

The final debate, which occurs during week 10 , will be open to the public (anyone you know is invited to attend). The press will ask the questions. The candidates will have the opportunity to pass out their campaign literature and show their TV commercials. At the end of the debate, the audience will vote. The press will conduct exit poll interviews with at least 10 people and write up their prediction of the winner based on the results. Note: The room for the last debate will be announced as soon as scheduled. All media releases (articles, debate questions, polls, etc.) will be provided to everyone in the class including the instructor. Be sure to always bring enough copies.

\section{Schedule}

Each Friday is devoted to the simulation

\section{Week Event}

1. The media learns who will be announcing their candidacy. The media meets to discuss questions for the first press conference.

2. The first "open" press conference, based on biographical background of candidates, is held. Each candidate takes the podium for 10 minutes. News articles due following Monday.

3. Candidates provide issue statements to the press. During the first half of class, prepare questions based upon candidates' issue statements. During the second half of class, conduct the press conference. News articles due following Monday.

4. The first candidate debate, sponsored by the League of Women Voters, is held. Candidates provide campaign brochures to the press; press provides campaign staff with issue areas to be addressed in debate; League of Women Voters [instructor] provides debate rules to press and candidates. The debate is held during the last 30 minutes of class. News articles due following Monday.

5. TIME OFF from campaign simulation. [Midterm scheduled]

6. Media will poll their readers: Do not come to class. Article on poll results due following Wednesday. Media will prepare to share their wisdom and insights about the election race during the "Meet the Press" roundtable scheduled for next week. Each campaign will film its TV commercial.

7. Campaigns receive poll results. First airing of political commercials. "Meet the Press" roundtable discusses the race, moderated by political scientist [instructor's name]. Campaigns watch and meet afterwards to develop a press release in response to the media pundits and write a prepared speech to be delivered the next Friday, which will serve as the basis for questions from the press.

8. Each candidate makes a 10 -minute speech followed by a 10 minute press conference. Editorial endorsement due following Monday.

9. TIME OFF to prepare for debates. Prior to the debate, the LWV [represented by the instructor] and the campaign staffs will agree upon the terms of the debate regarding whether or not a list of the journalists' potential questions are made available to the candidates before the debate. Debate questions from each media source are due the following Monday. If the candidates decide to restrict the debate to submitted questions, each campaign will also receive the questions on Monday. (Be sure to bring enough copies.)

10 Public Debate and Election. Thursday, $7 \mathrm{pm}$. Invite all your friends. Campaigns handout brochures. Debate begins with airing of television commercials. The debate is sponsored by the League of Women Voters, and features a panel of distinguished journalists moderated by political scientist [instructor's name].

Candidates will receive initial question from panelists every other turn. The candidate to receive the first question will be determined by a flip of the coin prior to the commencement of the debate. For each round of questioning, the candidate who receives the initial question will have two minutes to answer, followed by a one-minute response from the opponent, with a 30 -second rebuttal opportunity from the first candidate. The last 15 minutes will be reserved for audience questions. Upon the conclusion of the debate, citizens in the audience will complete their election ballots and drop them in boxes at the auditorium exits. The press will conduct exit poll interviews with at least 10 people and write up their prediction of the winner based on the results. Exit poll and election results will be announced the following Monday in class.

11. Monday. During the first half of class, members of the media form an election watch panel to discuss their reader/listener exit polls and make their predictions for the winner. Election results are announced. During the second half of class, the winner and loser each appear before the press with the appropriate acceptance or concession speech.

Thursday or Friday night: End of election year pizza party at instructor's house. 